\title{
Different conceptual constructs for modelling sedentary behaviour and physical activity: the impact on the correlates of behaviour
}

\author{
Nana Kwame Anokye ${ }^{1 *}$ and Emmanuel Stamatakis $2,3,4$
}

\begin{abstract}
Background: Research on the correlates of physical activity (PA) and sedentary behaviour (SB) to date has used independent prediction equations for each behaviour, without considering that they are both part of the same continuum of movement. This assumption of independence might lead to inaccurate estimates because common underlying latent variables may simultaneously influence the propensity to engage in PA and SB. This study tests empirically the interdependent nature of PA and SB by comparing independent equations (current approach in the literature), and joint estimators (a novel but unexplored approach). Using Health Survey for England 2008 data, accelerometry-accessed PA and SB were separately modelled (using ordinary least squared regressions - OLS) and then jointly (using seemingly unrelated regressions -SUR). We tested for diagonality, specification, and goodness of fit.

Findings: The best fit models were the ones that allowed for interdependence of the two movement-related behaviours ( $r h o=-0.156 ; p<0.001)$. The SUR showed more favourable properties compared to OLS models; producing lower standard errors and more consistent and efficient coefficients. The efficiency gain was more pronounced in the SB equation $\left(\mathrm{Chi}^{2}=92.75 ; \mathrm{p}<0.001\right)$.

Conclusion: Evidence from a large national population-wide accelerometry study suggests that accounting for the interdependent nature of PA and SB in prediction equations leads to more efficient modelling estimates. Further research using different samples is, however, required to fully understand the magnitude of efficiency gains accruable from using the joint estimators.
\end{abstract}

\section{Background}

Physical activity (PA) is an important health behaviour that is linked to cardiometabolic disease risk including obesity [1]. Sedentary behaviour (SB), any low-energyexpenditure activities $(\leq 1.5 \mathrm{MET})$ in a sitting or reclining posture (e.g. computer use, watching television, driving a car) [2], has been shown to be linked to health risks, even among people who engage in some PA [3-5]. Research to date has been treating PA and SB as distinct entities, although they are part of the same continuum and the above studies [3-5] highlighted some complex interrelationships between them.

\footnotetext{
* Correspondence: nana.anokye@brunel.ac.uk

${ }^{1}$ Health Economics Research Group (HERG), Brunel University, Uxbridge, Middlesex, London UB8 3PH, UK

Full list of author information is available at the end of the article
}

In the literature, prediction equations for $\mathrm{PA}$ and $\mathrm{SB}$ have largely been guided by a key assumption that individuals engage in PA and $\mathrm{SB}$ at two discrete time points and when they choose to do one they don't think of the other. In other words, the two behaviours are independent of each other. This has led many analysts to consider single-equation models, regressing for instance time spent on PA and SB separately on potential correlates [6]. As researchers don't always observe variables that may have synergies between the decisions to engage in $\mathrm{PA}$ and $\mathrm{SB}$, such as environmental factors (e.g. neighbourhood safety), just accounting for observables to study one behaviour at a time, ignoring the other, may be erroneous. This assumption of independence may be limiting because one could argue that individuals' time allocation in various activities are optimised by their 
satisfaction space and available time. People could know a priori possible scenarios in which they want to do various activities and gain a defined level of satisfaction. Predicting equations for PA and SB may therefore be interrelated to some extent and a failure to account for such inter-correlation could lead to inefficient estimates because it does not make optimal use of all available information [7]. Our earlier empirical work using population-based accelerometry data show a low-to-moderate correlation $($ rho $=-0.28)$ between moderate to vigorous PA and SB [8], suggesting that this area can be subjected to further empirical testing.

In the present study, we empirically tested the interdependent nature of PA and SB. We compare two different modelling frameworks, namely independent equations (which is current approach in the literature), and joint estimators (which is a promising and novel, but yet unexplored approach) using objectively-assessed PA and SB.

\section{Methods \\ Data}

The data source was the 2008 Health Survey for England (HSE08) which had a special focus on PA and SB. HSE08 was a cross sectional survey that drew a roughly nationally representative sample of people residing in private households in England. The sampling was based on a multi-stage stratified random sampling design that used the postcode address file as a sampling frame. A randomly selected sample of 4,507 adults (16 plus years) wore the accelerometer (Actigraph model GT1M, Pensacola, FL,USA). Respondents were to wear (at the waist) the Actigraph during waking hours for 7 consecutive days. Daily use was considered 'valid' if the Actigraph was worn for at least 10 hours. Kinesoft software (3.0.98) was used to analyse the raw accelerometry data to generate standardised measures. Further details on the survey and use of accelerometer in the HSE 2008 can be found elsewhere [9].

Like previously [8], moderate to vigorous physical activity (MVPA) was defined as a minutely count of $\geq 2020$ counts/minute and SB was defined as the number of daily minutes with a minutely accelerometry count of $<200$ counts/minute. We have previously found that in this dataset using different cut off points for sedentary time (e.g. $100 \mathrm{cpm}$ cut point) makes virtually no difference for analysis related to SB [8].

The explanatory factors we included are variables that are commonly correlated with PA and SB $[10,11]$. These included socio-demographic variables (age, income, sex, education, ethnicity, marital status, employment status, access to vehicle), household characteristics (number of children and adults in household), health indicators (having a limiting long-standing illness,), health behaviours (smoking and alcohol drinking status) and season of the year participants were measured. At the area level, included correlates were region of residence (strategic health authourity) and urbanisation.

\section{Statistical analysis}

Two multivariable modelling frameworks were used to estimate the factors that are associated with MVPA and SB. First, following the current empirical approach in the literature, separate OLS models were fitted for MVPA and SB respectively, assuming that MVPA and SB are independent. The estimates from such an approach served as baseline for us to test the joint nature of the two lifestyle choices. The assumption underlying this approach was that the error terms of both equations were not correlated [7]. The second approach fitted a seemingly unrelated regression model (SUR), which jointly and simultaneously estimates equations for MVPA and SB. This estimator accounts for the correlation between both equations. In practice, the seemingly unrelated model is estimated using two joint linear models that indicate an individual's participation in $\mathrm{MVPA}\left(\mathrm{Y}_{1}\right)$ and $\mathrm{SB}\left(\mathrm{Y}_{2}\right)$ correspondingly:

$$
\begin{aligned}
& \mathrm{Y}_{1}=\mathrm{X}_{1} \beta_{1}+\varepsilon_{1} \\
& \mathrm{Y}_{2}=\mathrm{X}_{2} \beta_{2}+\varepsilon_{2}
\end{aligned}
$$

where $X_{1}$ and $X_{2}$ are regressors of $\mathrm{PA}$ and $\mathrm{SB}$ respectively. $X_{1} \neq X_{2}$ and we also require $T>K_{i}$ (where $T=$ total observations; $\mathrm{K}_{\mathrm{i}}=$ total regressors).

$$
\varepsilon=\left[\varepsilon_{1}, \varepsilon_{2}\right]
$$

regressors are assumed to be strictly exogenous:

$$
\mathrm{E}\left[\varepsilon \mid \mathrm{X}_{1}, \mathrm{X}_{2}\right]=0
$$

For any given equation the disturbance is homoscedastic and that the errors terms are uncorrelated across observations but correlated across Eqs. (1) and (2). Therefore:

$$
\mathrm{E}\left[\varepsilon_{1} \varepsilon_{2} \mid \mathrm{X}_{1}, \mathrm{X}_{2}\right]=\sigma_{12} \mathrm{I}_{\mathrm{T}}
$$

Comparative analysis of the SUR and OLS was conducted with a number of indicators. Using the test for diagonality, Breusch Pagan test, we examined whether SUR compared with the OLS leads to efficiency gain. This test produces a LM statistic that adds the squared correlations between the residual vectors for equations (for MVPA, and SB), with a null hypothesis of diagonality, zero contemporaneous covariance between the disturbances of the two equations [12]. The size of standard errors of estimated parameters of both equations was also compared in relative terms (specified as: (StandardError ${ }_{\mathrm{OLS}}{ }^{-}$

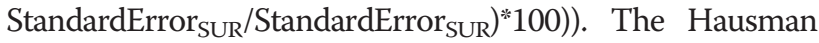
specification test was used to check which estimator produced better consistent and efficient estimates. 
Table 1 Descriptive statistics of variables

\begin{tabular}{|c|c|c|}
\hline Variables & Observations & Mean(SD)/\%" \\
\hline \multicolumn{3}{|l|}{ Dependent } \\
\hline $\begin{array}{l}\text { Time spent undertaking moderate to } \\
\text { vigorous physical activity per day (mins) }\end{array}$ & 2289 & $28.2(25.4)$ \\
\hline $\begin{array}{l}\text { Time spent undertaking sedentary } \\
\text { activity per day (mins) }\end{array}$ & 2289 & $472.1(126.4)$ \\
\hline \multicolumn{3}{|l|}{ Explanatory variables } \\
\hline Age & 2289 & $51.7(18)$ \\
\hline \multicolumn{3}{|l|}{ Income (\%) } \\
\hline$>44200$ & 451 & 19.7 \\
\hline$<17789$ & 680 & 29.7 \\
\hline$>/=17789$ and $<27317$ & 389 & 17 \\
\hline$>/=27317$ and $<44200$ & 403 & 18 \\
\hline missing & 366 & 16 \\
\hline \multicolumn{3}{|l|}{ Sex } \\
\hline Males & 1,030 & 45 \\
\hline Females & 1,259 & 55 \\
\hline \multicolumn{3}{|l|}{ Educational qualification } \\
\hline No qualification & 601 & 26.3 \\
\hline Degree equivalent & 472 & 20.6 \\
\hline Higher education below degree & 271 & 11.8 \\
\hline 'A'/ 'O' level/NVQ & 714 & 31.2 \\
\hline Other qualification & 231 & 10.1 \\
\hline \multicolumn{3}{|l|}{ Ethnicity } \\
\hline White British & 244 & 10.7 \\
\hline Other & 2,045 & 89.3 \\
\hline \multicolumn{3}{|l|}{ Marital status } \\
\hline Single & 533 & 23.3 \\
\hline Married and living with partner & 1255 & 54.8 \\
\hline Other & 501 & 21.9 \\
\hline \multicolumn{3}{|l|}{ Employment status } \\
\hline Unemployed & 195 & 8.5 \\
\hline Employed & 1244 & 54.4 \\
\hline Retired & 693 & 30.3 \\
\hline Looking after family & 157 & 6.9 \\
\hline \multicolumn{3}{|l|}{ Health status } \\
\hline Limiting illness & 603 & 26.3 \\
\hline Non-limiting illness & 506 & 22.1 \\
\hline No illness & 1,180 & 51.6 \\
\hline \multicolumn{3}{|l|}{ Smoking status } \\
\hline Non-smoker & 1,075 & 47 \\
\hline Former smoker & 743 & 32.5 \\
\hline Smokers & 465 & 20.3 \\
\hline Missing & 6 & 0.3 \\
\hline \multicolumn{3}{|l|}{ Drinking status } \\
\hline Almost every day & 324 & 14.2 \\
\hline
\end{tabular}

Table 1 Descriptive statistics of variables (Continued)

\begin{tabular}{|c|c|c|}
\hline Five or six days a week & 129 & 5.6 \\
\hline Three or four days a week & 363 & 15.9 \\
\hline Once or twice a week & 603 & 26.3 \\
\hline Once or twice a month & 291 & 12.7 \\
\hline Once every couple of months & 147 & 6.4 \\
\hline Once or twice a year & 184 & 8 \\
\hline $\begin{array}{l}\text { Not at all in the last } \\
12 \text { months/non-drinkers }\end{array}$ & 243 & 10.6 \\
\hline Missing & 5 & 0.2 \\
\hline \multicolumn{3}{|l|}{ Number of children in household } \\
\hline No child & 1932 & 84.4 \\
\hline One children & 190 & 8.3 \\
\hline Two or more children & 167 & 7.3 \\
\hline \multicolumn{3}{|l|}{ Number of adults in household } \\
\hline One adult & 515 & 22.5 \\
\hline Two adults & 1427 & 62.3 \\
\hline Three or more adults & 347 & 15.2 \\
\hline \multicolumn{3}{|l|}{ Seasons } \\
\hline Winter & 589 & 25.7 \\
\hline Autumn & 708 & 30.9 \\
\hline Summer & 442 & 19.3 \\
\hline Spring & 550 & 24 \\
\hline \multicolumn{3}{|l|}{ Region of residence } \\
\hline North east & 162 & 7.1 \\
\hline North west & 339 & 14.8 \\
\hline Yorkshire and the Humber & 248 & 10.8 \\
\hline East midlands & 271 & 11.8 \\
\hline West midlands & 232 & 10.1 \\
\hline East of England & 271 & 11.8 \\
\hline London & 190 & 8.3 \\
\hline South east coast & 176 & 7.7 \\
\hline South central & 133 & 5.8 \\
\hline South west & 267 & 11.7 \\
\hline \multicolumn{3}{|l|}{ Urbanisation } \\
\hline Urban & 1841 & 80.4 \\
\hline Town \& fringe & 203 & 8.9 \\
\hline Village, hamlet and isolated dwellings & 245 & 10.7 \\
\hline \multicolumn{3}{|l|}{ Access to vehicle } \\
\hline Yes & 362 & 15.81 \\
\hline No & 1,927 & 84.19 \\
\hline
\end{tabular}

*Mean (SD) refers to numbers with parenthesis beside them. Otherwise, percentages.

The models were estimated with sampling weights that were calculated as the inverse of the probability of being a respondent in a household multiplied by the household 
weight which accounts for non-responding households [9]. As individuals are nested within households, the models were estimated with cluster (household identifier) to allow the errors associated with individuals residing in a household to correlate with each other.

The PA data was log-transformed using the default logarithmic scale of $[u=\log 10]$ to improve normality of its distribution. Marginal effects (or elasticity for continuous correlates) were computed to show relative impact of a correlate on MVPA or SB. In the case of equations for MVPA, marginal effects were expressed as exponential values because the associated geometric means (as showed by the marginal effect) arising from log transformed dependent variables has to be converted to the arithmetic mean for comparison with the original data for interpretation. The t-test was used to examine whether missing data occurred completely at random. If not at random, missing values for explanatory variables were treated as separate categories and included in the models in order to avoid biased estimates [13]. The threshold for statistical significance was set at $\leq 5 \%$ in all analyses. Multiple comparisons were adjusted for using Bonferroni correction. All analyses were undertaken using Stata version 13.

\section{Results}

\section{Description of sample}

Descriptive statistics for the variables are presented in Table 1. A total of 2,289 adults had valid accelerometry data and were included in the analyses. On the average, people spent 28 minutes/day participating in MVPA, and $472 \mathrm{mi}-$ nutes undertaking SB per valid day. The mean age of sample was $52(\mathrm{SD}=18)$ years. Most were female $(55 \%)$, married and living with their partners $(55 \%)$ and employed $(54 \%)$. Few were obese $\left(\mathrm{BMI} \geq 30 \mathrm{~kg} / \mathrm{m}^{2}\right)$ or current smokers (20\%), while the large majority were drinkers (89\%), defined as drinking alcohol at once or twice a year.

Table 2 Estimation results of seemingly unrelated regression model (SUR) and ordinary least square (OLS): physical activity

\begin{tabular}{|c|c|c|c|c|c|}
\hline \multirow[t]{3}{*}{ Explanatory variables } & \multicolumn{4}{|l|}{ Physical activity } & \multirow{3}{*}{$\%$ difference in SE (SUR vs. OLS) } \\
\hline & \multicolumn{2}{|l|}{ OLS } & \multicolumn{2}{|l|}{ SUR } & \\
\hline & Coef. $(M E)^{a}$ & $S E^{b}$ & Coef. $(M E)^{a}$ & $S E^{b}$ & \\
\hline Age & $-0.030(-0.470)^{* * *}$ & 0.002 & $-0.030(-1.596)^{* * *}$ & 0.002 & 0.57 \\
\hline \multicolumn{6}{|l|}{ Sex } \\
\hline \multicolumn{6}{|l|}{ Males $^{c}$} \\
\hline Females & $-0.253(0.776)^{* * *}$ & 0.046 & $-0.253(0.759)^{* * *}$ & 0.046 & 0.28 \\
\hline \multicolumn{6}{|l|}{ Health status } \\
\hline \multicolumn{6}{|l|}{ Limiting illness ${ }^{c}$} \\
\hline Non-limiting illness & $0.532(1.702)^{* * *}$ & 0.073 & $0.531(1.744)^{* * *}$ & 0.073 & 0.32 \\
\hline No illness & $0.492(1.636)^{* * *}$ & 0.065 & $0.491(1.704)^{* * *}$ & 0.065 & 0.27 \\
\hline \multicolumn{6}{|l|}{ Drinking status } \\
\hline \multicolumn{6}{|l|}{ Almost every day } \\
\hline Five or six days a week & $0.363(1.438)^{* *}$ & 0.112 & $0.363(1.415)^{* *}$ & 0.112 & 0.41 \\
\hline Three or four days a week & $0.106(1.112)$ & 0.090 & $0.107(1.101)$ & 0.090 & 0.34 \\
\hline Once or twice a week & $0.076(1.079)$ & 0.077 & $0.077(1.028)$ & 0.077 & 0.32 \\
\hline Once or twice a month & $-0.013(0.987)$ & 0.089 & $-0.012(0.920)$ & 0.088 & 0.39 \\
\hline \multicolumn{6}{|l|}{ Once every couple of } \\
\hline months & $-0.102(0.903)$ & 0.108 & $-0.101(0.848)$ & 0.108 & 0.30 \\
\hline Once or twice a year & $-0.233(0.792)$ & 0.109 & $-0.230(0.763)$ & 0.109 & 0.39 \\
\hline $\begin{array}{l}\text { Not at all in the last } 12 \\
\text { months/non-drinkers }\end{array}$ & $-0.257(0.773)$ & 0.109 & $-0.253(0.762)$ & 0.108 & 0.40 \\
\hline \multicolumn{6}{|l|}{ Access to vehicle } \\
\hline \multicolumn{6}{|l|}{$\mathrm{No}^{c}$} \\
\hline Yes & $-0.228(0.796)^{* *}$ & 0.068 & $-0.210(0.865)^{* *}$ & 0.067 & 1.94 \\
\hline Constant & $4.187^{* * *}$ & 0.127 & $4.172^{* * *}$ & 0.125 & 1.37 \\
\hline Observations & 2268 & & 2268 & & \\
\hline
\end{tabular}

${ }^{\mathrm{a}}$ Coefficient (Marginal Effects/Elasticity); ${ }^{\mathrm{b}}$ Standard Error; ${ }^{\mathrm{c} O m i t t e d}$ category ${ }^{*}$ Exponentiated ME $>1$ (negative effect), exponentiated ME $<1$ (negative effect); Significance level of $1 \%\left({ }^{* *}\right), 5 \%\left({ }^{* *}\right)$; Hausman specification test (null hypothesis: difference in coefficients in two models is not systematic): Chi2 (26) $=0.10 ; p=1.000$. 
Only three variables (income, smoking status, and drinking status) had missing observations. 'Income' had the highest number of missing observations $(n=366)$, whereas 'drinking status' had the lowest $(n=5)$. Daily MVPA of respondents with missing values were different from those without (income: $26.28(\mathrm{SD}=1.25)$ vs 28.61 (0.56), $\mathrm{p}$ value $=0.107$; smoking status: $60.33(\mathrm{SD}=23.41)$ vs $28.15(0.53)$, $\mathrm{p}$ value $=0.002$; drinking status: $76.60(\mathrm{SD}=$ $28.18)$ vs $28.13(0.53)$, p value $<0.001)$.

\section{Comparison of modelling frameworks}

Tables 2 and 3 show estimates for the results of SUR and OLS models for MVPA, and SB respectively. The MVPA equation was found to be correlated with that of $\mathrm{SB}$ equation $(r=-0.156 ; \mathrm{P}<0.001)$, with the Breusch-Pagan test for independence of the residual vectors of both equations suggesting such correlation is not by chance.

Second, further evidence of efficiency gains via the SUR can be ascertained by comparing standard errors. The magnitude of reduction in standard errors achieved via SUR was found to be relatively more for the estimated parameters of SB equation compared to the MVPA one (see sixth columns of Tables 2 and 3 ).
Third, the Hausman specification test suggested that for $\mathrm{SB}$, the parameters of the SUR model were systematically different from those of the OLS $\left(\mathrm{Chi}^{2}=92.75 ; \mathrm{P}<0.001\right)$ and produced better consistent and efficient estimates. Both models, however, yielded similar coefficients in the case of MVPA. Table 2 shows both SUR and OLS indicate that older individuals, females, and individuals with access to vehicles were associated with lower levels of MVPA. Conversely, individuals who had non-limiting illness (or no illness) undertook more PA per day. Compared with individuals who drank alcohol almost every day, people who drank on 5 or 6 days/week spent more time undertaking MVPA ( $\mathrm{ME}=1.415$ to 1.438 ). The correlates of SB differed from that of MVPA in terms of type of correlates as well as direction of correlation (when same correlates were found across both behaviours; except for gender). As shown on Table 3, SB was positively correlated with age, and educational qualification. Females, individuals in better health, and smokers spent less SB time.

\section{Discussion}

This is the first study, to our knowledge, to conduct an empirical test as to which of the two conceptual

Table 3 Estimation results of seemingly unrelated regression model (SUR) and ordinary least square (OLS): sedentary behaviour

\begin{tabular}{|c|c|c|c|c|c|}
\hline \multirow[t]{3}{*}{ Explanatory variables } & \multicolumn{4}{|l|}{ Sedentary behaviour } & \multirow{3}{*}{ \% difference in SE (SUR vs. OLS) } \\
\hline & \multicolumn{2}{|l|}{ OLS } & \multicolumn{2}{|l|}{ SUR } & \\
\hline & Coef. $(M E)^{a}$ & $S E^{b}$ & Coef. $(M E)^{a}$ & $S E^{b}$ & \\
\hline Age & $2.150(0.219)^{* * *}$ & 0.325 & $2.239(0.253)^{* * *}$ & 0.315 & 3.25 \\
\hline \multicolumn{6}{|l|}{ Sex } \\
\hline \multicolumn{6}{|l|}{ Males $^{c}$} \\
\hline Females & $-30.439(-30.439)^{* * *}$ & 6.226 & $-32.612(-30.166)^{* * *}$ & 6.105 & 1.98 \\
\hline \multicolumn{6}{|l|}{ Educational qualification } \\
\hline \multicolumn{6}{|l|}{ No qualification ${ }^{c}$} \\
\hline Degree equivalent & $52.937(52.937)^{* * *}$ & 10.924 & $53.544(47.168)^{* * *}$ & 10.472 & 4.29 \\
\hline Higher education below degree & $30.421(30.421)$ & 10.656 & $31.813(23.752)$ & 10.206 & 4.40 \\
\hline 'A'/'O' level/NVQ & $11.724(11.724)$ & 8.954 & $14.274(15.429)$ & 8.553 & 4.69 \\
\hline Other qualification & $3.658(3.658)$ & 12.213 & $3.135(2.859)$ & 12.006 & 1.72 \\
\hline \multicolumn{6}{|l|}{ Health status } \\
\hline \multicolumn{6}{|l|}{ Limiting illness ${ }^{c}$} \\
\hline Non-limiting illness & $-17.590(-17.590)$ & 7.960 & $-14.058(-14.351)$ & 7.594 & 4.82 \\
\hline No illness & $-25.601(-25.601)^{* * *}$ & 6.774 & $-26.444(-22.749)^{* * *}$ & 6.710 & 0.96 \\
\hline \multicolumn{6}{|l|}{ Smoking status } \\
\hline \multicolumn{6}{|l|}{ Non-smoker } \\
\hline Former smoker & $6.512(6.512)$ & 6.851 & $2.999(0.218)$ & 6.589 & 3.97 \\
\hline Smokers & $-24.422(-24.422)^{* *}$ & 9.383 & $-29.638(-25.870)^{* *}$ & 9.050 & 3.68 \\
\hline Constant & $393.172^{* * *}$ & 27.129 & $393.525^{* * *}$ & 26.778 & 1.31 \\
\hline Observations & 2289 & & 2268 & & \\
\hline
\end{tabular}

${ }^{a}$ Coefficient (Marginal Effects/Elasticity); ${ }^{\mathrm{b}}$ Standard Error; ${ }^{\mathrm{c} O m i t t e d}$ category; Significance level of $1 \%\left({ }^{* *}\right), 5 \%\left({ }^{* *}\right) ;$ Hausman specification test (null hypothesis: difference in coefficients in two models is not systematic): Chi2 (44) $=92.75 ; p=0.000$. 
constructs (i.e. whether PA and SB are jointly determined or independent) is likely to be more efficient modelling framework. A search of SCOPUS (largest bibliographic database) and PUBMED, conducted in May 2014, located no applications of joint estimators for PA and SB, although two previous studies have applied SUR to PA and sport or diet $[14,15]$. The findings from the analysis in this study showed a contemporaneous correlation between the errors terms of equations for SB and PA, suggesting that the two movement behaviours are interdependent and hence the utility of the SUR particularly for SB (albeit small efficiency gains).

In addition, the SUR provided relatively less uncertain coefficients than the OLS estimator, especially in the case of SB. Therefore, joint estimators were found in this study to be a more efficient modelling framework than the current approach in the literature (single estimators). Notably, if there was no evidence of a contemporaneous correlation between the SB and MVPA equations, the SUR would have been equivalent to equation by equation via OLS. Nonetheless, the SUR would have still been worthwhile because it has an attractive feature of allowing restrictions to be imposed and appropriate tests conducted across parameters in the different equations. For example, joint significance tests for variables that are common to both equations could be undertaken.

Our analysis is not free from an important limitation though; but we judge that the implications of this limitation for our conclusions if any are only minimal. For example, our analysis had unequal observations on which the MVPA and SB equations were estimated (the former had 20 less observations). Noted by McDowell [16], fitting a SUR on equations that have varying number of observations could lead to loss of information because observations that are unavailable for both equations are discarded, potentially leading to more uncertain estimates. In our case, because the excluded observations were not systematically different from the included ones and fitting the equations on the full set of imputed observations resulted in similar findings, it is unlikely that the current conclusions would change if actual information were available on those 20 observations.

Notwithstanding the limitation, the findings from this study do offer an important consideration for future research on SB and PA. The key message here is that to achieve more efficient and tighter estimates, analysis of the correlates of PA and SB in particular ought to use simultaneous joint equations that account for the intercorrelation between PA and SB. Further research using different samples is, however, required to fully understand the magnitude of efficiency gains accruable from using the joint estimators. Only by examining this, will we be in a position to accurately determine the importance of joint estimators in this area.

\section{Conclusion}

This is the first study examining the efficiency gains accruable to joint estimators (e.g. SUR based analysis) into the associated factors of PA and SB. However, it would be important to replicate these results in other datasets in order to provide firmer conclusions on the most appropriate modelling framework for analysing PA and SB.

\section{Abbreviations \\ PA: Physical activity; SB: Sedentary behaviour; SUR: Seemingly unrelated regression; OLS: Ordinary least squares.}

\section{Competing interests}

The authors declare that they have no competing interests.

\section{Authors' contribution}

NKA conceived concept of paper with inputs from ES. Dataset was prepared by both authors. NKA conducted the statistical analysis. Both authors drafted and reviewed the manuscript and approved the final draft. All authors read and approved the final manuscript.

\section{Acknowledgments}

We thank UK Data Archive, University of Essex, Colchester for providing us with the 2008 Health Survey for England (HSE) data. The survey was undertaken by National Centre for Social Research and University College London, Department of Epidemiology and Public Health and sponsored by the Information Centre for Health and Social Care. A draft version of this paper was discussed at the Health Economics Research Group's (HERG) paper day, and we would like to thank participants, in particular Dr Subhash Pokhrel, for their valuable inputs. The views expressed in the publication are those of the authors and not necessarily those of the institutions.

\section{Author details}

${ }^{1}$ Health Economics Research Group (HERG), Brunel University, Uxbridge, Middlesex, London UB8 3PH, UK. 'Exercise and Sport Sciences, Faculty of Health Sciences, University of Sydney, Sydney, Autralia. ${ }^{3}$ Charles Perkins Centre, University of Sydney, Sydney, Australia. ${ }^{4}$ Physical Activity Research Group (UCL-PARG), Department of Epidemiology and Public health, University College London, London, UK.

Received: 30 June 2014 Accepted: 12 December 2014 Published: 16 December 2014

\section{References}

1. Henson J, Yates T, Biddle SJH, Edwardson CL, Khunti K, Wilmot EG, Gray LJ, Gorely T, Nimmo MA, Davies MJ: Associations of objectively measured sedentary behaviour and physical activity with markers of cardiometabolic health. Diabetologia 2013. doi:10.1007/s00125-013-2845-9.

2. Tremblay MS: Standardized use of the terms "sedentary" and "sedentary behaviours". Appl Physiol Nutr Metab 2012, 37:540-542.

3. Chau JY, Grunseit AC, Chey T, Stamatakis E, Brown WJ, Matthews CE, Bauman $A E$, van der Ploeg HP: Daily sitting time and all-cause mortality: a metaanalysis. PLOS ONE 2013, 8(11):e80000. doi:10.1371/journal.pone.0080000.

4. Chomistek AK, Manson JE, Stefanick ML, Lu B, Sands-Lincoln M, Going SB, Garcia L, Allison MA, Sims ST, LaMonte MJ, Johnson KC, Eaton CB: Relationship of sedentary behavior and physical activity to incident cardiovascular disease. J Am Coll Cardio/ 2013, 61:2346-2353.

5. van der Ploeg HP, Chey T, Korda RJ, Banks E, Bauman A: Sitting time and all-cause mortality risk in 222497 Australian adults. Arch Intern Med 2012, 172:494-500.

6. Brodersen NH, Steptoe A, Williamson S, Wardle J: Sociodemographic, developmental, environmental, and psychological correlates of physical activity and sedentary behaviour at age 11 to 12. Ann Behav Med 2005, 29:2-11

7. Greene W: Econometric analysis. Internationalth edition. Pearson Prentice Hall: Upper Saddle River NJ; 2008

8. Stamatakis E, Hamer M, Tilling K, Lawlor D: Sedentary time in relation to cardio-metabolic risk factors: differential associations for self-report vs accelerometry in working age adults. Int J Epidemiol 2012, 41:1328-1337. 
9. Health and Social Care Information Centre on Health Survey for England 2008: physical activity and fitness: Report. London: 2009.

10. Biddle S, Cavill N, Gorely T, Griffiths M, Jago R, Oppert JM, Raats M, Salmon J, Stratton G, Vicente-Rodríquez G, Butland B, Prosser L, Richardson

D: Sedentary behaviour and obesity: review of the current scientific evidence. London: Department of Health; 2010.

11. van Stralen MM, De Vries H, Mudde AN, Bolman C, Lechner L: Determinants of initiation and maintenance of physical activity among older adults: a literature review. Health Psychol Rev 2009, 3:147-207.

12. Baum CF: An introduction to modern econometrics using Stata. Boston: Stata Press; 2006.

13. Petrou S, Kupek E: Social capital and its relationship with measures of health status: Evidence from the Health Survey for England 2003. Health Econ 2008, 17(1):127-143.

14. Villar GJ, Lera-Lopez F, Suarez MJ: Estimation of a structural model of the determinants of the time spent on physical activity and sport: evidence for Spain. J Sports Econ 2011, 12:515-537.

15. Christian TJ: Trade-Offs between commuting time and health-related activities. J Urban Health 2012, 89:746-757.

16. McDowell A: From the help desk: seemingly unrelated regression with unbalanced equations. Stata J 2004, 4:442-448

doi:10.1186/1756-0500-7-921

Cite this article as: Anokye and Stamatakis: Different conceptual constructs for modelling sedentary behaviour and physical activity: the impact on the correlates of behaviour. BMC Research Notes 2014 7:921

\section{Submit your next manuscript to BioMed Central and take full advantage of:}

- Convenient online submission

- Thorough peer review

- No space constraints or color figure charges

- Immediate publication on acceptance

- Inclusion in PubMed, CAS, Scopus and Google Scholar

- Research which is freely available for redistribution 